\title{
Transgenic Technology and Animal Welfare
}

\author{
BERNARD DIXON
}

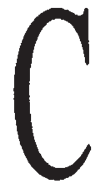

ampaigns against new developments in science and technology can, paradoxically, help to promote them, as Mike Ward commented recently in Bio/Technology (13:1048). Citing Martin Bauer of the London School of Economics and the coauthors of Resistance to New Technologies (Cambridge University Press, Cambridge, U.K.), Ward highlighted the possibility of "protest as a cleansing pain."

What better example than transgenic animals? As we move cautiously toward using animals to produce pharmaceuticals, we should not only expect searching criticism of these techniques and their implications. We should welcome such criticism. No society is well served when the concerns of even a minority of its members are suppressed or ignored.

So patience and humility are in order-though they need conscious effort. When Tim O'Brien's Gene Transfer and the Welfare of Animals (1995. Compassion in World Farming Trust. Charles House, 5A Petersfield, Hants, GU32 3EH, U.K.) landed on my desk recently, my immediate response was one of irritation. The cover of this report by the Compassion in World Farming Trust was the first irritant. It carries a garish photograph of a pig that is either dead or seriously ill, with no explanation of its significance.

The second irritant was O'Brien's concluding remarks about "bioscience companies scrambling to be the first to patent the most highly productive mutant farm animal, with little regard for the discarded embryos, the failed experimental 'material,' the 'superovulated' donor animals that have to be sacrificed for company profits." Overlooking a long tradition of conventional animal breeding, O'Brien continues: "The transgenic farm animal must take its place down on the family farm, for its deliberately unbalanced physiology and metabolism mean that it can never be at home in the natural world, into which its ancestors developed during millions of years of patient evolution."

Other passages in this document are as tendentious as those conclusions. Yet patience is repaid, because many of the arguments are in fact more soundly based that a first cursory glance suggests. The report highlights both immediate and conjectural long-term concerns that can not be lightly dismissed. Already, for example, some 90 percent of Belgian Blue cattle, thanks to selective breeding, need to have their caves delivered by cesarean section. More distantly, what of the possibility that undesirable effects of transgenes may come to light in future generations, when they interact in unforeseen ways with other parts of a recipient species' genome?

I take issue with the Compassion in World Farming Trust in my belief that any dangers associated with transgenic animal technology can be addressed by the sensitive application of humane principles and by a vigilant surveillance as the technology develops.

I do not know whether Tim O'Brien was in the audience to hear Alan Colman, research director of Edinburgh-based PPL Therapeutics, speak on this subject during the Biotechnica meeting, held recently in Hanover, Germany. If he was present, it would surely have been difficult for him to sustain the view that animals are being ill-treated in the interests of corporate profit.

For this was a talk as thoroughly imbued with concern for animal welfare and sensitivity toward public and regulatory concerns, as any I have heard. Indeed, it is hardly surprising that the well-being of PPL Transgenics' animals is paramount for a company that hopes to have $\alpha$-1-antitrypsin, made by sheep (Bio/Technology, 11:1263, 1993), in clinical trials next year. The drug will be used to treat patients with emphysema caused by a genetic deficiency of ATT. As Colman points out, it is essential that the transgenic sheep enjoy normal health and have a normal lifespan.

Clearly, the inception of this new technology, like every other beneficent technology, has had some adverse consequences. But both enlightened selfinterest and the social, political and regulatory climate mean that animals are simply not going to be misused in the way some opponents allege. PPL Therapeutics have, for example, engineered mice to produce erythropoietin (EPO), but the animals were adversely affected, so EPO will not be made in this way.

I do have a caveat, however. The title of Alan Coleman's Hanover talk was "The transgenic mammary gland as a bioreactor." My dictionary defines bioreactor as "a vessel used to carry out a biological reaction." Continued use of this expression will, I believe, needlessly arouse fears that biotechnologies really are cynical beings hell-bent on treating animals as insensible machines. Let us stamp it out now. 